\title{
EXPERIMENTAL INVESTIGATION ON THE EFFECT OF VARYING PURGE FLOW IN A NEWLY COMMISSIONED SINGLE STAGE TURBINE TEST FACILITY
}

\author{
Daniel Payne, Vasudevan Kanjirakkad \\ Thermo-Fluid Mechanics Research Centre \\ School of Engineering and Informatics \\ University of Sussex \\ Falmer, Brighton \\ Email: d.payne@sussex.ac.uk
}

\begin{abstract}
In order to produce efficient engines it is essential for gas tur-bine designers to understand the interaction between the primary and secondary air systems in critical parts of the engine. One of these is the first stage turbine, where the ingress of the hot an-nulus air into the rotor stator cavity could be catastrophic due to the increased heat load on the disc posts and on the rotor blades themselves (through reduced cooling). To ensure that this does not happen, contactless seals (rim seals) are built into the outer radius of the rotating disc. Additionally, a secondary air flow rate must be appropriately set in order to 'purge' the hot air that could be ingested into the rim seal cavity. However, this purge airflow could cause deterioration of the turbine performance as it re-joins the main annulus flow at the interface between the rim seal cavity and the main annulus. The deterioration in performance is pri-marily due to the difference in kinematic (flow velocity and mass flow) and thermodynamic (density, enthalpy) properties of the two stream of air. It is therefore essential to understand the optimum seal geometry and purge flow rates required to prevent the ingestion of the hot annulus air while maintaining the required turbine performance. In this paper we present experimental test results from a single stage turbine facility, the Rim Seal (RiSe) rig, at the University of Sussex. The turbine stage incorporates a model rotor-stator cavity system that is representative of the first stage turbine in a gas turbine engine. The facility is capable of generating disc cavity rotational Reynolds numbers of the order
\end{abstract}

of $2.2 \times 10^{6}$ and axial Reynolds number of the order of $0.7 \times 10^{6}$, while operating at a pressure ratio of 2.5 . The paper will present the salient features of the test facility, the various instrumentation employed, and the operating specifications of the stage. The paper will discuss the effect of varying the purge flow for a fixed operating point of the turbine. Results presented will include typical mission profiles, cavity radial temperature distribution, and the measured cavity sealing effectiveness.

\section{INTRODUCTION}

Ever since the first gas turbine rotated under it's own power, engineers have been striving to improve performance and efficiency. As designers have increased the operating pressures within the turbine, the subsequent increase in temperature has caused the need of a secondary air system to ensure the safe operation of the hottest regions of the engine. As this system removes air from the main annulus, it has a detrimental impact on both performance and efficiency of the gas turbine. It is therefore very important for research to be conducted to understand how the two different air systems interact.

The interaction between the hot main annulus air and the sealing flow of the first stage turbine has been a research topic that has been investigated for over 50 years. This includes the effects caused by the rotation of the disk in the rotor stator cavity, known as Rotationally Induced (RI) Ingress, and the pressure variation which is caused by the air flowing over the stator vanes, 
known as Externally Induced (EI) Ingress. Initial research focusing on RI ingress began with simple rigs which included a rotor and stator, but with no blades and vanes. Bayley and Owen [1] used a pair of coaxial disks of approximately $750 \mathrm{~mm}$ diameter. Both disks were manufactured from acrylic to allow flow visualisation, whilst also measuring pressure on the surface of the stator. They derived an equation for $C_{w, \min }$ using the different seal geometries that were tested.

$$
C_{w, \min }=0.61 G_{c} R e_{\phi}
$$

where $G_{c}$ is the seal clearance ratio. Phadke and Owen [2], in the first of their three part paper series, investigated seven different seal geometries using a rotor and stator rig in a quiescent environment. Using flow visualisation techniques they captured the bulk motion of the flow within the cavity, and the changes which were caused by the different seal geometries.

One of the early research in the area of EI ingress was conducted using an experimental rig which included a representative flow path geometry as described by Abe et al. [3]. Their rig consisted of a stator row of 27 vanes, but with a rotor without blades. They showed that ingress could be dominated by the pressure asymmetries of the air flowing over the vanes, rather than the rotational effects of the rotor stator cavity. In the final part of their three part series, Phadke and Owen [4] simulated the pressure field caused by the stator vanes by partially blocking the annulus. From their results they produced the following relationship to determine the minimum sealing flow rate required to seal the rotor stator cavity.

$$
C_{w, \min }=\pi K G_{c}\left(2 C_{p, \max }\right)^{\frac{1}{2}} R e_{w}
$$

where $C_{p, \max }$ is the pressure coefficient and $\mathrm{K}$, an empirical constant, was calculated as 0.6 for a range of seals. The work of Green and Turner [5] expanded on what was completed by Abe et al. [3] to add a bladed rotor. Their rig consisted of a stator of 18 vanes and a rotor of 32 blades. The mainstream air was provided by a centrifugal fan which meant that the conditions were close to ambient. By using measurements of pressure and Nitrous Oxide gas concentration they were able to determine that the presence of the blades had a positive impact on the levels of ingestion, however even at the highest sealing flow rate tested there was still some ingestion.

The first build of the turbine test that is now the RiSe rig uses produced by Gentilhomme et al. [6]. They adapted a Rolls Royce Gnome helicopter engine free power turbine and gearbox to form the main body of the rotor. A titanium rotor blisk of 59 blades and an aluminium stator of 26 vanes was then incorporated. They found that the ingestion of the annulus air into the upstream rotor stator cavity caused an increase in the levels of swirl. The facility used by Gentilhomme et al. [6], was then evolved into a two stage axial turbine with a stator well configuration by firstly Dixon et al. [7] and then later with modifications by Eastwood et al. [8]. It consisted of a stator of 39 vanes and a rotor of 78 blades for both stages. One of the focuses of that research [8] was to measure the re-ingestion of egress from the upstream rotor stator cavity into the stator well. This was completed using $\mathrm{CO}_{2}$ gas concentration measurements. The work of Eastwood et al. [8] investigated multiple geometrical changes to the stator well, showing the versatility of the test rig. Palafox et. al. [9] developed a 1.5 stage turbine rig that can test a range of different type rim seals. Their rig is highly instrumented and includes high frequency pressure measurements and $\mathrm{CO}_{2}$ gas concentration. Their facility allows for supply mass flow up to $7 \mathrm{~kg} / \mathrm{s}$ at $200^{\circ} \mathrm{C}$. Patinios et. al. [10] presented results from a 1.5 stage axial turbine test rig. It features titanium bliscs for both stators and rotors which have 32 vanes and 48 blades respectively. The annulus air is supplied via 32 circular inlet pipes and the rotor is driven using a dynamometer. They used a double seal arrangement for both the upstream and downstream rotor stator cavities, and found that the ingress remained within the outermost section.

In the front stages of an axial turbine, an important region of interest is the secondary air system associated with the rotor-stator disc cavity and the interaction of this system with the main annulus gas path. The rotor-stator cavity is supplied with secondary coolant air (that is originally bled from the front stage compressors) in order to cool the stator and the rotor disc surfaces. This air is then re-introduced into the main annulus through a sealing system located at the outer radius (rim-seal) that is designed to reduce the ingestion of hot gas from the annulus into the rotor-stator cavity. Early research began with simple test rigs which included coaxial discs where one was kept stationary as the other was rotated. Following from this the most recent experimental rigs are highly instrumented scaled models of actual axial turbines, to try to best match the conditions seen in engines. This paper introduces the Rim Seal, RiSe, rig which is a new single stage axial turbine test configuration at the ThermoFluid Mechanics Research Center (TFMRC) at the University of Sussex. It is the latest generation of axial turbine test rigs at the TFMRC, obtained following a series of major modifications from the research rig configuration as described by Eastwood [11]. A brief outline of the remaining sections of the paper is as follows. A detailed description of the RiSe rig is provided first that includes the details of the ancillary equipment required, the main components of the test section and the various instrumentation employed for collecting aerothermal data. This is followed by the presentation of experimental data from the baseline test case. This includes measurement of sealing effectiveness and stage performance at a range of purge flow conditions that were tested. Finally, conclusions from the present research activity are listed.

\section{TEST FACILITY}

This section describes the facility and main components of the RiSe Rig. Figure 1 shows a block diagram representing the 


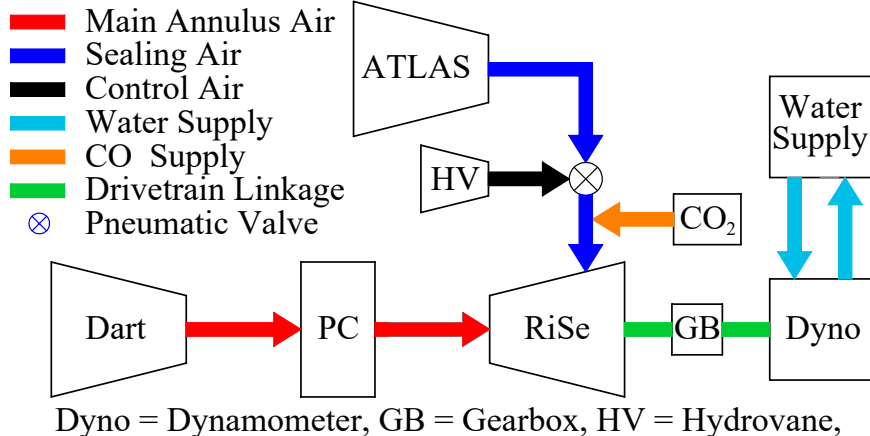
$\mathrm{PC}=$ Plenum Chamber

Figure 1. Block diagram showing the RiSe rig and the enabling auxiliary systems

main hardware that is required by the rig. The air supply for the main annulus flow is provided by a centrifugal compressor driven by a Rolls-Royce Dart turboprop engine that was adapted for this purpose at the Thermo Fluid Mechanics Research Centre (see Turner et al. [12] for more information). To ensure safe operation of the Dart engine and to meet the design conditions of the RiSe rig, it is necessary to bypass much of the flow from the driven compressor. The Dart operator can adjust one of two bypasses to maintain the mass flow rate while maintaining a constant inlet pressure and temperature. The length of a single experiment on the rig is usually limited by the capacity of the installed fuel tank and care is taken to design test runs with this limitation in mind. The maximum continuous run time is typically 4 hours.

The main annulus air first enters a plenum chamber. The air then exits the plenum chamber through a bell-mouth inlet, situated inside the plenum chamber, before entering the straight pipework that feeds the inlet to the rig. This is required to reduce any swirl or pressure asymmetry at the inlet of the rig, and is essential due to the location of the engine plant.

The sealing air is provided by an Atlas Copco ZT250 oil free screw compressor, which is passed through an Atlas Copco FD700 dryer. If gas concentration measurements are to be carried out to trace the coolant flow, then this air can be seeded with $\mathrm{CO}_{2}$ upstream of the rig. This is explained further in a later section.

The rotor disc of the single stage research turbine used in the current test configuration is directly mounted onto the shaft of a modified Rolls-Royce Gnome (turboshaft) engine gearbox. The turbine shaft speed is therefore geared down approximately three times before it is coupled with a Heenan \& Froude DPY590 water brake dynamometer that absorbs the turbine power. The closed loop water supply for the dynamometer is cooled using a rooftop heat exchanger before being collected in a large storage tank from where it is pumped back into the brake using an electric pump. This is essential to maintain the water inlet tem- perature to the dynamometer during prolonged test runs.

Figure 2 shows a schematic of the cross-section of the RiSe Rig test section. All of the components in the rim seal region are manufactured from Titanium 6AL-4V. This includes the stator ring which consists of 36 vanes, and the rotor which has 72 blades, both are manufactured as blisks. The rotor casing is manufactured from Ferritic Stainless Steel, chosen as it has a similar coefficient of thermal expansion to titanium, the material of the rotor, thereby reducing the possibility of differential expansion between the rotor and the casing and a potential contact between the two. To further reduce the impact an unintended rub between the rotor and it's casing would cause, an abradable coating is applied over the inner band of the rotor casing. Other components in the stationary frame where the labyrinth seals are located also use the same abradable coating material, to remove the possibility of metal-to-metal contact.

As the RiSe rig is an evolution of previous turbine rigs, see Eastwood [11], many of the components are the same, or have been modified to incorporate the newly designed turbine stage. This is true for the hub and casing which is upstream of the stator. There are 14 struts ( 2 in Figure 2 ) which feature a symmetric airfoil, and these, apart from acting as structural support, allow for essential pipes and cables to cross the annulus flow path. One of the beneficial changes in comparison to the previous two stage build, is that the turbine doesn't require any additional bearings to those in the output shaft bearing housing. This helps to reduce the number of required components and also decreases the complexity of running the RiSe rig.

\section{Sealing Air Supply}

The sealing air enters the rig through two of the 14 struts ( 2 in Figure 2). It is then passed through a water cooled heat exchanger, situated inside the rig inlet nose-cone, which ensures that the air temperature remains as low as possible during the length of an entire test. Even with insulations around the nosecone ( 1 in Figure 2) cavity, this air will pick up heat by travelling through the two struts. This necessitates the use of the heat exchanger for ensuring that the temperature delta between the sealing air and the main annulus air is as large as possible. This heat exchanger is also cooled externally by purging the nosecone cavity with air during the test. This air is supplied by a Hydrovane HV37 compressor, and is directed through an external water cooled heat exchanger.

Downstream of the heat exchanger the air flows over the rotating telemetry housing (3 in Figure 2), and will then either enter the stationary pre-swirl cavity or exhaust directly into the lower purge cavity through the labyrinth seal. Finally the air enters the upstream rotor stator cavity and can exhaust through either the rim seal or by disc-post leakage. This leakage is simulated by 72 through holes at $\mathrm{r} / \mathrm{b}=0.92$ which allow for approximately $0.5 \%$ of main annulus flow to exhaust into the downstream rotor stator 


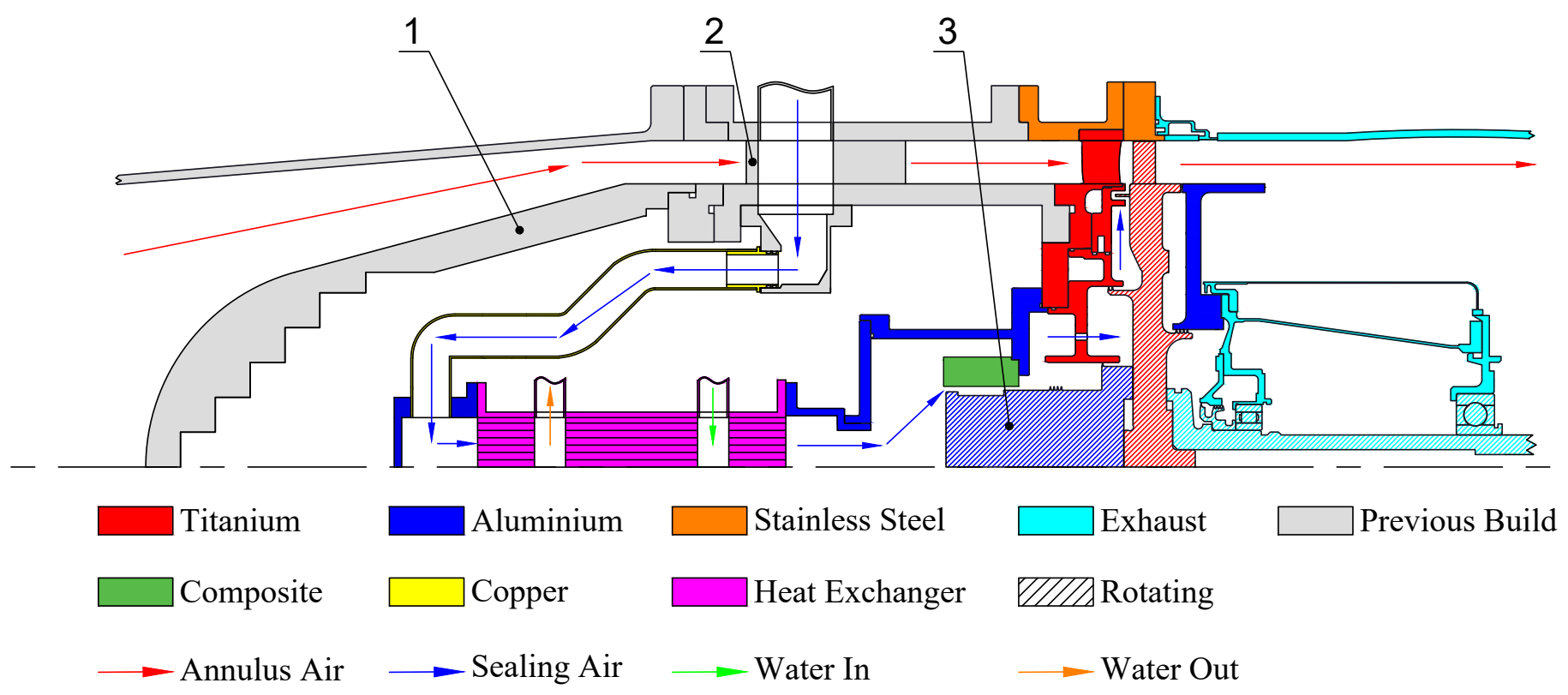

Figure 2. The turbine test section and other internal flow and component details of the RiSe rig

cavity. This flow can be quantified using the $C_{d}$ of the holes and the pressure drop between the upstream and downstream cavities, and is assumed to be constant throughout the range of purge flow rates tested. During the design process the size of the holes were set to ensure the flow rate through them was approximately constant for the range of sealing flows tested. The initial CFD staudies (not shown in this paper) suggested that the variation in disc-post leakage is of the order of $+/-0.05 \%$ over the range of purge flows tested.

\section{Rim Seal Geometry}

All the results presented in this paper corresponds to the geometric configuration shown in this section. Figure 3 shows a representation of the rim seal region. The rotating part of the seal is a single angel-wing and this is located within the stator buffer cavity. The radial height, $s_{c, r a d}$, which is measured between the rotating angel-wing and the rim seal radius (b), is used to calculate $G_{c}$. All clearances shown are measured as cold build clearances. The material selection makes sure that there is negligible differential expansion between components.

\section{INSTRUMENTATION}

The RiSe rig is heavily instrumented, with over 400 measurement locations distributed around the test section and external systems. The majority of these are for the measurement of temperature and pressure, however there are also measurements

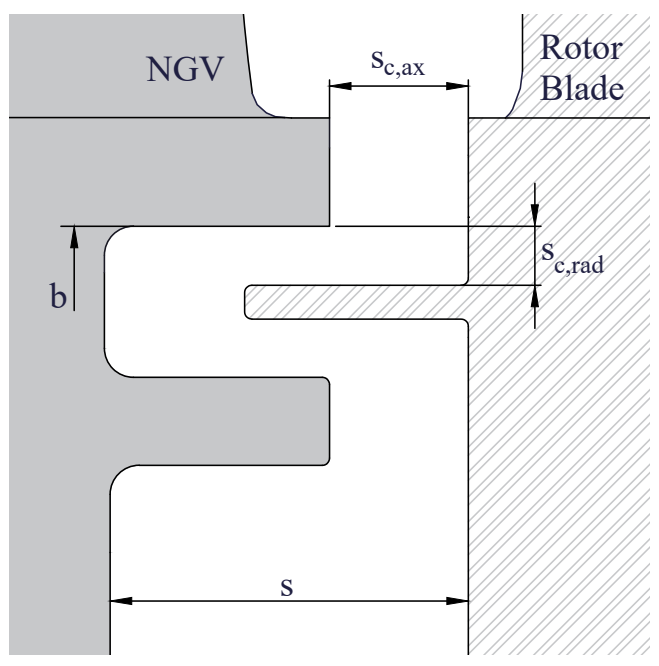

Figure 3. Rim seal region geometry parameters (stator shown filled and rotor shown hatched)

of $\mathrm{CO}_{2}$ concentration, mass flow rate and tip clearance.

\section{Temperature}

All measurements of temperature are taken using K-type thermocouples (TCs). There are over 100 measurements in the stationary frame, and over 40 in the rotating frame. There are leading edge temperature rakes on three of the stator vanes to 
capture the total inlet conditions and multiple rakes downstream of the rotor to measure the outlet conditions. Within the rim seal region there are over $30 \mathrm{TCs}$ to measure both air and metal temperature, and these are positioned around the circumference and clocked to the position of the vane trailing edges. Additionally there are measurements of oil, bearing and water temperatures of the drivetrain equipment for essential monitoring.

The stationary frame temperature measurements use two different data acquisition (DAQ) systems. The majority of the measurements use a modified National Instruments SCXI, where all of the TCs are terminated in thermally insulated boxes. Each of the boxes has three PRTs to monitor the cold junction temperature, which are connected to an Agilent 34970A data logger. The remaining stationary temperature measurements are made using two Agilent 34901A cards that are plugged into available slots within the same data logger as mentioned above. All of the TCs in these cards use the in-built cold junction compensation, and they also use the standard calibrations.

All the rotating measurements are made using the rotor mounted telemetry system which was custom manufactured by Datatel. It has the capacity to connect to 26 TCs and measures the cold-junction temperature using two in-house calibrated PRTs. It can record data at a frequency of up to $10 \mathrm{~Hz}$.

\section{Pressure}

There are about 150 pressure measurement locations all of which are in the stationary reference frame. In most cases these pressure measurements are co-located with the stationary frame temperature measurements as described earlier. There are rakes in the annulus to measure the total pressure at the inlet on the vane and downstream of the rotor. There are static pressure measurements throughout the rim seal region and test section.

There are six Scanivalve DSA 3217 units of various ranges from 5 psi to 100 psi that are employed for these measurements. Each DSA unit contains 16 pressure sensors some of which are also connected to a multiplexer valve to enable measurement of pressure at more locations than the number of channels available across all the DSA units. The pressure locations measured through the multiplexer units are logged at a lower frequency than those connected directly to the DSA. The reduced measuring frequency is a disadvantage, however this system does allow for the user to easily switch redundant pressure tappings.

\section{Carbon Dioxide Concentration}

It was mentioned previously in the paper that the sealing flow could be seeded with $\mathrm{CO}_{2}$. This allows for samples to be taken within the rig to understand the mixing between the annulus and sealing flows. These samples can be taken from the rim seal region or downstream of the rotor in the annulus. The $\mathrm{CO}_{2}$ gas from the storage bottle is mixed with the purge flow (sealing air) supply using a manual valve to set the required flow rate. The $\mathrm{CO}_{2}$ concentration in the purge flow supply, and all other air sampling locations in the rig test-section, is measured using Vasiala GMM 220 Infra-red $\mathrm{CO}_{2}$ analysers. As there are only three such analysers available, a system to selectively connect them to the various individual concentration measurement locations is devised. All such $\mathrm{CO}_{2}$ sampling locations are also doubled up as pressure measurement locations. Every pressure line that is also shared with the $\mathrm{CO}_{2}$ sampling system is connected to one of three VICI 16 channel PC controlled actuators. Each of these are connected to an analyser, and a manual on-off valve allows the rig operator to switch between pressure and $\mathrm{CO}_{2}$ sampling modes.

During the test each of the three analysers takes a measurement of the $\mathrm{CO}_{2}$ concentration in the purge supply air, and this is compared against measurements made in the cavity and annulus. Due to the limited length of time that the Dart facility can be operated, $\mathrm{CO}_{2}$ concentration is only measured for a selection of the purge flow rates that are tested during a given experiment.

\section{Additional Measurements}

In addition to the above mentioned key variables that enables the performance of the cavity-annulus flow interaction to be assessed, the following additional quantities are also measured during the run. These measurements are essential to establish predefined operating conditions for the rig and also to ensure its safe operation throughout the run.

Mass Flow Rate There are three mass flow meters which are required for the different air flow streams.

The main annulus flow is monitored with an in-house manufactured and instrumented venturi, which is installed between the driven Dart compressor and the RiSe rig plenum chamber. The main air supply pipe work has straight sections for at least ten pipe diameters upstream and five downstream of the venturi to comply with the recommendation of the British Standards.

The sealing flow is measured using a factory calibrated Alicat M3000 linear flow meter. This is located within the test cell, and upstream of where the $\mathrm{CO}_{2}$ supply is mixed with the sealing flow.

The $\mathrm{CO}_{2}$ flow is measured using a Kobold linear flow meter which is located upstream of the $\mathrm{CO}_{2}$ flow manual control valve.

Displacement During the commissioning process it was found that the casing of the RiSe rig was moving in relation to the rotor, causing an un-equal tip clearance around the circumference. By running the rig up to design temperatures it was possible to understand the direction in which the casing was moving and by how much, and this allowed a solution to be implemented. This involved altering how the casing and gearbox were secured to the bed plate of the rig. 
TABLE 1. Operating conditions for baseline test case

\begin{tabular}{ll}
\hline Parameter & Value \\
\hline Rotational Reynolds number, $R e_{\phi}$ & $2 \times 10^{6}$ \\
Axial Reynolds number, $R e_{w}$ & $7 \times 10^{5}$ \\
Flow coefficient, $\phi$ & 0.3 \\
Pressure Ratio, PR & 2.5 \\
NGV Exit Mach number & 0.7 \\
Non dimensional purge mass flow, $C_{w}$ & $4000-13,000$
\end{tabular}

The tip clearance is measured using a MicroEpsilon S05 eddy current sensor. This is connected to a MicroEpsilon multiNCDT 300 signal processor which has measuring frequency of $10 \mathrm{kHz}$. This is lower than the blade passing speed and so it is unable to capture the displacement of each blade tip. As the sensor only has a range of $0.5 \mathrm{~mm}$, any readings out of range can easily be filtered out, to give an average reading of the tip gap. To ensure uniformity in tip clearance over the annulus, there were 2 sensors located around the circumference.

As only the blade tip clearance is being measured, the position of the angel wing is an unknown. The actual position could be estimated using a mechanical model that incorporates the local metal temperature measurements.

Torque A load cell is installed on the load arm of the dynamometer to allow the torque to be measured. The load cell has been calibrated in-situ by systematically applying known amounts of weight and by noting down the corresponding load cell response.

Speed Both the speed of the rotor and dynamometer are measured continuously during every test. Both use a magnetic pick-up type sensor, with the output counting the number of spikes. The rotor sensor uses a four spoke target which is connected to the cap of the telemetry housing. The dynamometer sensor uses the output gear wheel for it's target.

\section{RESULTS}

As described in the previous sections, the RiSe turbine rig incorporates an aerodynamically engine representative high pressure turbine stage and the associated rotor-stator cavity with rimseal arrangement. The detailed instrumentation of the main annulus flow path and the various cavity regions enable detailed understanding of the physics of the interaction between the purge

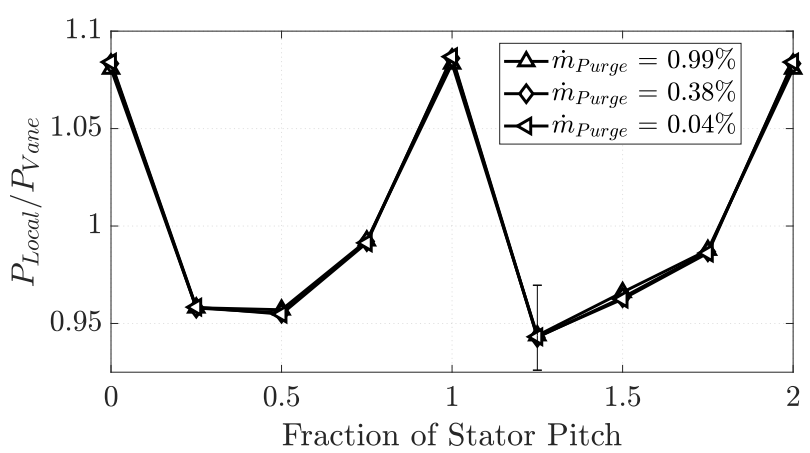

Figure 4. Vane trailing edge hub normalised pressure profile with maximum variation around circumference shown

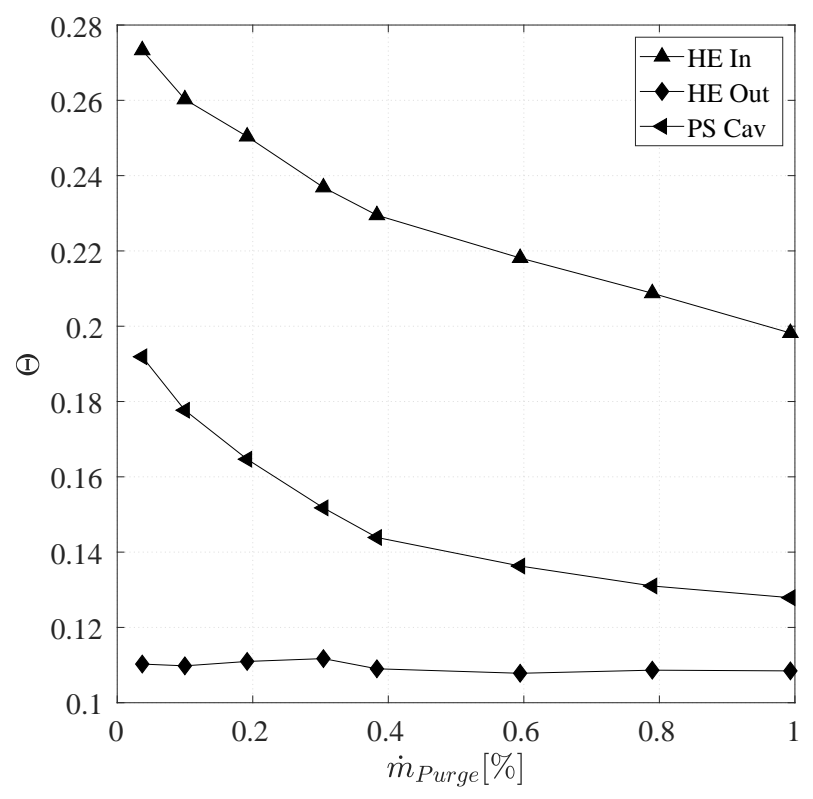

Figure 5. Variation of the non-dimensional temperature of the sealing/purge air supply as the purge flow rate is reduced

flow and the main annulus flow. Although not subjected to extensive analysis at this stage, the following sections present a number of useful data plots that one could use to discern the turbine operating conditions and the nature of the flow interaction as described above.

Table 1 shows the operational conditions of the RiSe rig for which example results are presented in this paper. The inlet conditions to the turbine are controlled by the Dart, however the rig operator can adjust the dynamometer load to set the rotor speed and also set the purge mass flow rate.

The turbine section of the RiSe rig has been designed to simulate engine realistic conditions. The geometry of the vane was designed to ensure that a realistic stator vane pressure field is 

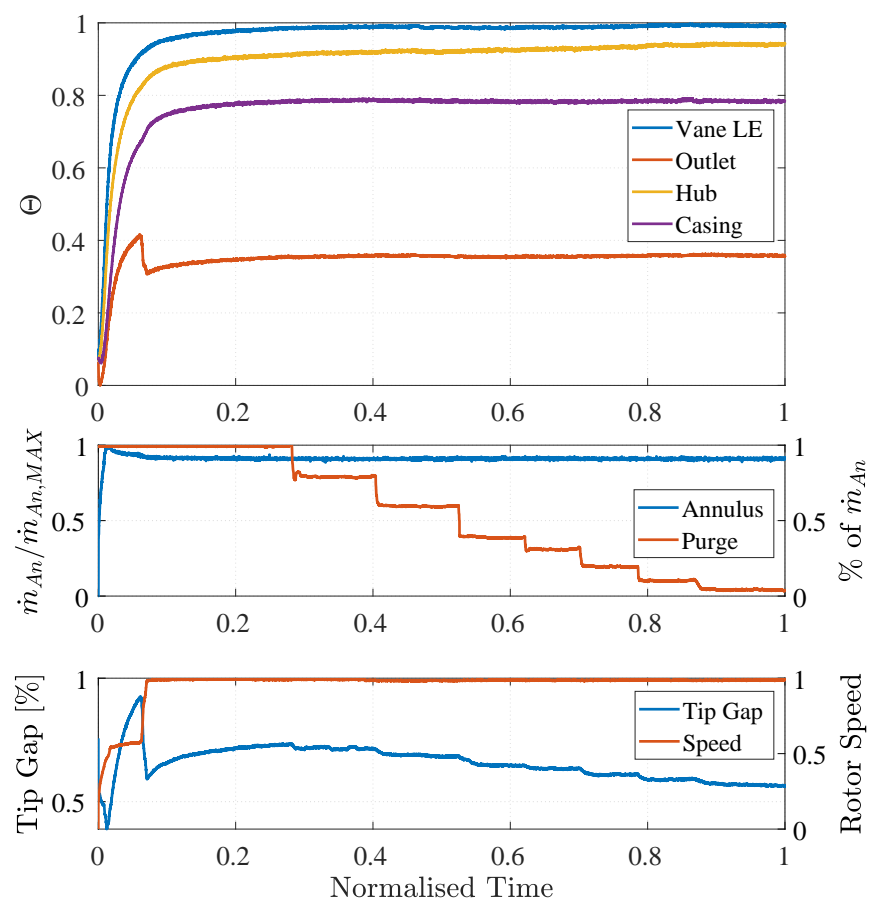

Figure 6. Plots showing variation of key operating parameters and non-dimensional temperatures at selected locations during a typical test run

present at the upstream of the trench. Figure 4 shows the average pressure variation (normalised using the vane average and local measurements) across two vane pitches. The data shows how this distribution is affected by purge flow variation $<1 \%$. It is clear that the stator exit pressure field is too dominant to be affected by the purge flow range tested. This plot is an average of six vanes which are positioned around the circumference of the rig. The largest difference between any three locations was found to be 0.04 .

Figure 5 shows the non-dimensional temperature $(\Theta)$ of the purge supply as it travels from the inlet of the water cooled heat exchanger installed within the nosecone (see Figure 2) to the preswirl cavity.

$$
\Theta=\frac{T_{\text {Local }}}{T_{\text {Annulus }}}
$$

For the entire range of purge flows tested the non-dimensional outlet temperature can be seen to only vary by 0.02 (whereas the annulus inlet only varies by 0.01 ), showing that the heat exchanger is very effective, and that the air temperature is almost kept at the heat exchanger water temperature. However, in comparison the temperature of the purge air in the pre-swirl cavity does increase with the reduction in purge mass flow rate. This is caused by heat pickup from the stationary components, as there is no insulation between them and the components of the annulus. If there was no heat exchanger, then the temperature measured in the cavity would be much higher, considering the temperature at which it enters the heat exchanger. The delta temperature between the annulus and purge supply (across the purge flow range tested) is too low to cause any density differences.

Figure 6 shows measured non-dimensional temperatures in the annulus at the vane leading edge, in comparison to the outlet rake and the metal temperatures at both the hub and casing of the stator. Also included is the purge supply mass flow rate, showing the range of sealing flow rates that were tested. It takes approximately $20 \%$ of the run time for the rig to reach a thermal steady state at the first sealing flow setting. Following this the $\mathrm{CO}_{2}$ concentration measurements are made, then the sealing flow is reduced and the process is repeated, a time of $5 \%$ of the entire test length is needed to ensure the rig is at an appropriate steady state.

As there is no heat exchanger for the main annulus supply, the inlet temperature to the rig can change based on the ambient conditions on the day of the experiment. This is also reflected in the outlet rake and casing measurements, however the hub temperature does change due to the reduction in sealing flow rate.

Figure 6 also shows the tip clearance for the complete experiment. There is almost a $0.3 \%$ decrease in tip clearance as the rotor speed increases from an initial warm-up to the design speed. There is approximately a $0.2 \%$ change in clearance from highest to lowest purge flow rates.

Figure 7 shows measured non-dimensional temperatures, $\theta$ in the rotor stator cavity.

$$
\theta=\frac{T_{\text {Local }}-T_{\text {Purge }}}{T_{\text {Annulus }}-T_{\text {Purge }}}
$$

where $T_{\text {Purge }}$ is measured at the pre-swirl cavity where $\mathrm{r} / \mathrm{b}=0.46$ and $T_{\text {Annulus }}$ is an average of the NGV leading edge air TCs. As can be seen in Figure 7 the change in mass flow rate of the purge flow has the greatest effect on temperatures for $0.81 \leq \mathrm{r} / \mathrm{b} \leq 0.92$. As the purge mass flow rate reduces, the difference between the metal and air temperatures decrease $(\mathrm{at} r \mathrm{r} / \mathrm{b}=0.81$ ) showing how the ingress is increasing the temperature in this cavity.

Figure 8 shows the variation in swirl $(\beta)$ in the core of the cavity evaluated as a fraction of the local solid body rotation, as purge flow rate is varied. Note that the expression below for $\beta$ assumes that the radial velocity component is negligible compared to the circumferential velocity.

$$
\beta=\sqrt{\frac{P_{R}-P_{R_{0}}}{1 / 2 \rho \Omega^{2} b^{2}\left(R^{2}-R_{0}^{2}\right)}}
$$

where density is evaluated at $R$, and $R_{0}$ is the lower of the two radii where pressure is measured. In comparison with the experimental data of Gentilhomme et. al. [6] and the correlation by Daily et. al. [13], the calculated swirl is notably higher through- 


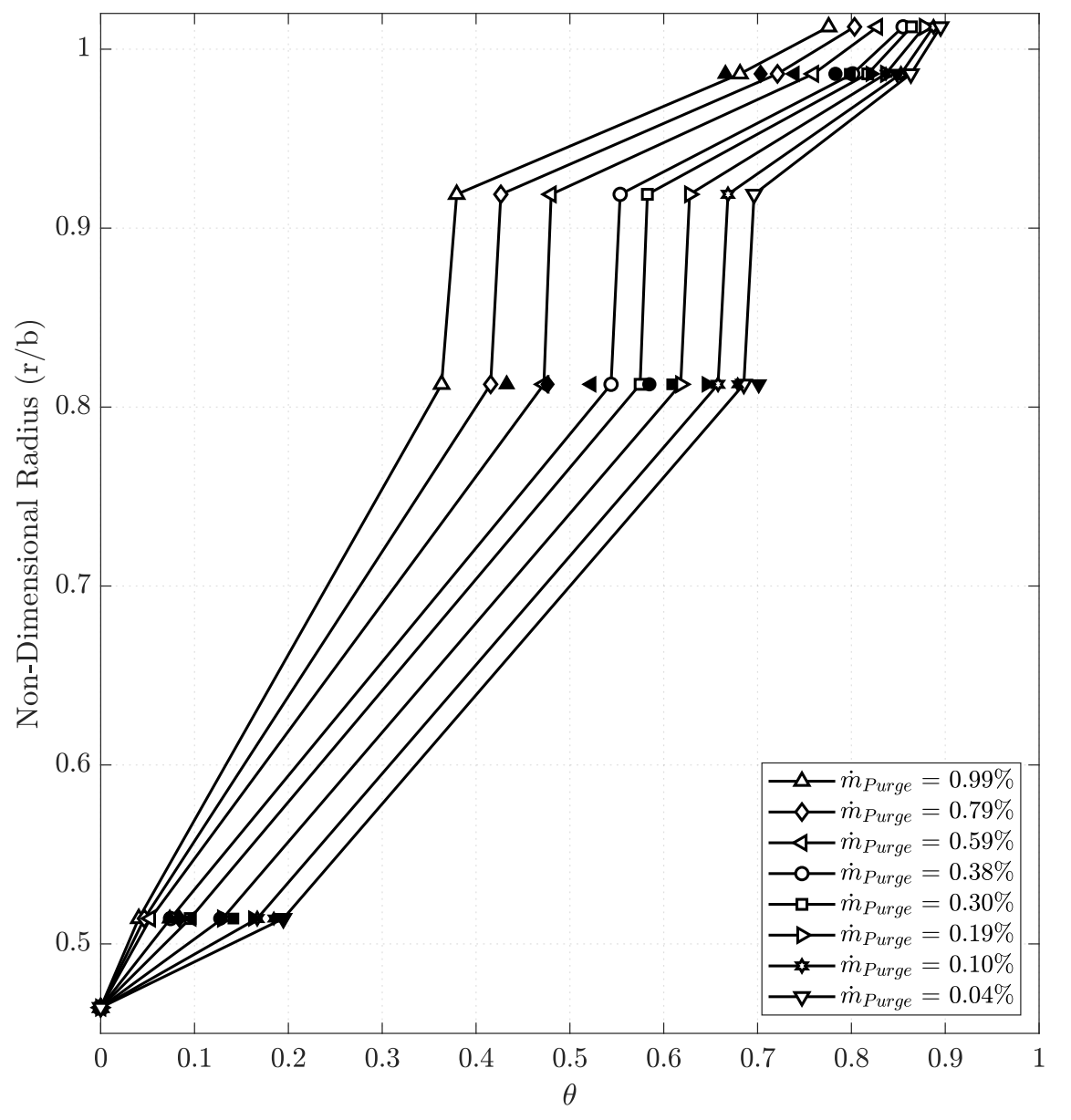

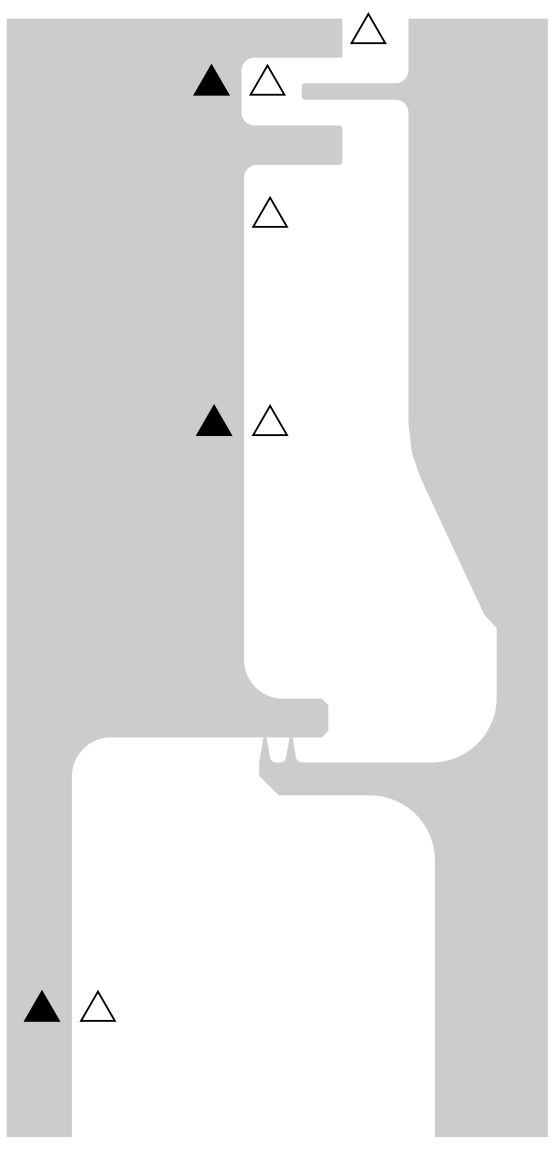

Figure 7. Plot showing measured $\theta$ values up the stator surface of the rotor stator cavity for all purge flow rates tested (filled symbols $=$ metal TCs, un-filled symbols $=$ air TCs)

out the range of purge flow tested. The correlation by Daily et. al. [13] does not take into consideration the superimposed external (annulus) flow and the sinusoidal pressure variation setup by the vanes. In the studies by Gentilhomme et. al. [6] there is no rotor disc post leakage below the rim seal as present in the current study. This leakage removes roughly $50 \%$ of the purge flow. The effect of both the sinusoidal pressure forcing and the leakage of sealing flow past the disc post both contribute to the increased swirl.

\section{Sealing Effectiveness}

Different purge flows can be compared to understand how the sealing effectiveness changes as purge is decreased. Figure 9 shows $\mathrm{CO}_{2}$ concentration based sealing effectiveness measure- ments for the five lowest sealing flow rates.

$$
\varepsilon_{c}=\frac{c_{\text {Local }}-c_{\text {Annulus }}}{c_{\text {Purge }}-c_{\text {Annulus }}}
$$

To help quantify the relationship between ingress and egress for a rotor stator cavity it is possible to use the theoretical model of Owen [14] to calculate the ratio of discharge coefficients, $\Gamma_{c}$, using the following equation (derived by Sangan et. al. [15]), which is applicable to a rotor-stator cavity subjected to EI ingress.

$$
\frac{C_{w, 0}}{C_{w, \text { min }}}=\frac{\varepsilon}{\left[1+\Gamma_{c}^{-2 / 3}(1-\varepsilon)^{2 / 3}\right]^{3 / 2}}
$$

where $\Gamma_{c}$ is the ratio of the discharge coefficients for egress and ingress. For $\mathrm{r} / \mathrm{b}=0.81, \Gamma_{c}=1.9$ which suggests that ingress is dominating in this cavity. However, it is not possible to use the same model for locations above $r / b>0.92$. One difference between the capabilities of the model and the experimental setup 


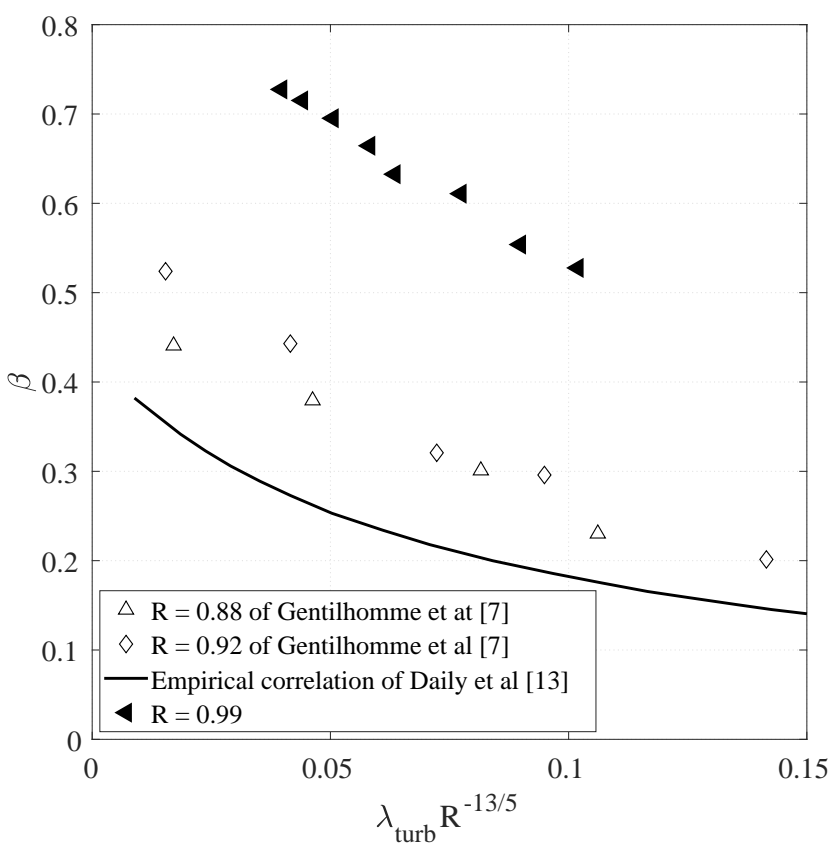

Figure 8. Cavity swirl calculated from pressure measurements compared with experimental data and empirical correlations from published literature

is that the model doesn't account for any leakage paths of air out of the cavity which aren't the rim seal. As the RiSe Rig has disk post leakage at $\mathrm{r} / \mathrm{b}=0.92$, this change of the flow conditions in the cavity are not considered in the model.

If the disc walls around the cavity are adiabatic and if the windage effects are negligible (both statements are false for this test), one could use the measured cavity air temperature to define sealing effectiveness.

$$
\varepsilon_{T}=1-\frac{T_{\text {Local }}-T_{\text {Purge }}}{T_{\text {Annulus }}-T_{\text {Purge }}}
$$

Figure 10 shows values of air temperature based sealing effectiveness measured at a range of $0.5 \leq \mathrm{r} / \mathrm{b} \leq 0.99$ on the stator for the entire range of sealing flows tested. It shows that there are three distinct regions, due to the geometry of the cavity. The air is always hottest in the trench $(\mathrm{r} / \mathrm{b}=1.01)$, which is expected, and as the sealing flow is reduced, the temperature in the buffer cavity $(r / b=0.99)$ gets closer to it. For the location radially below the seal $(\mathrm{r} / \mathrm{b}=0.81)$, there is the largest change in measured temperature. Finally in the purge supply cavity $(\mathrm{r} / \mathrm{b}=0.51)$ it can be seen that the relationship between temperature and sealing flow rate does change, unlike at the other locations where they respond in a near linear curve.

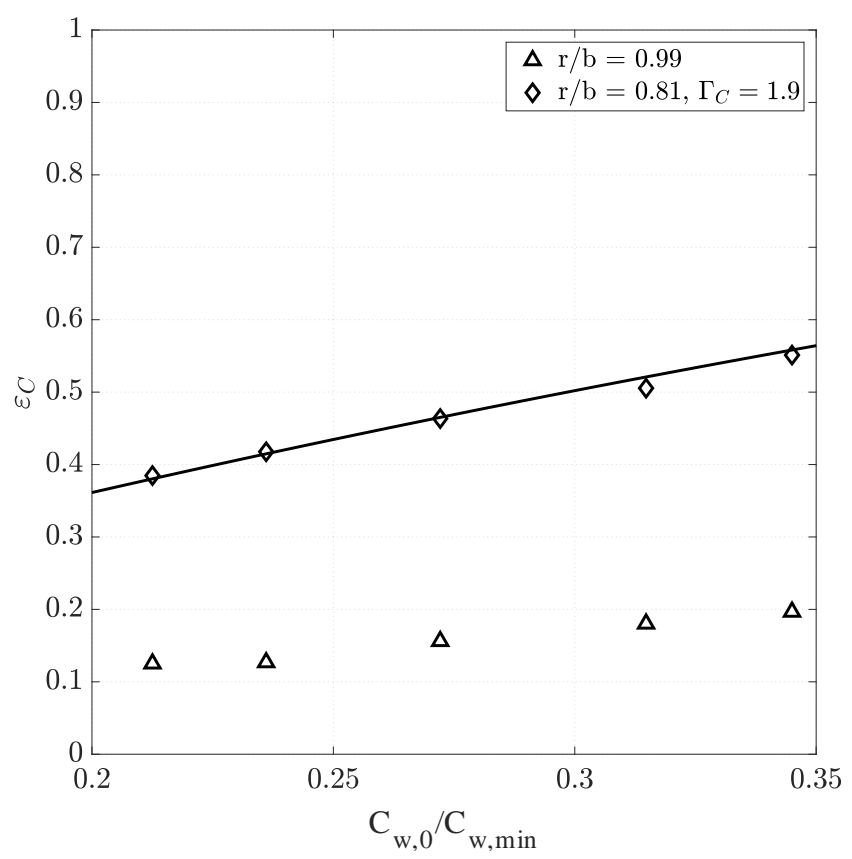

Figure 9. Sealing effectiveness using $\mathrm{CO}_{2}$ concentration measurements in the upstream rotor stator cavity

In comparison with Figure 9, Figure 10 also shows that the buffer cavity has more ingestion than the rotor stator cavity. Another comparison between this and Figure 9 is that again the Owen model will only fit against data of $\mathrm{r} / \mathrm{b} \leq 0.92$. For $\mathrm{r} / \mathrm{b}=$ $0.51, \Gamma_{c}=0.1$ suggesting egress is dominating. This is expected as the sealing air should be egressing from this cavity into the rotor stator cavity, and there may only be ingress at very low purge flow rates. At $\mathrm{r} / \mathrm{b}=0.81$, the calculated $\Gamma_{c}$ value is 10 . This is much higher than the $\Gamma_{c}$ that results from fitting the Owen model for the concentration based effectiveness $\left(\varepsilon_{c}\right)$ at the same radius. Since, at a given radius, one would expect the same level of ingress calculated from either methods, it is clear that the temperature based effectiveness evaluation is corrupted by the heat transferred into the cavity as a result of windage and conduction.

By directly comparing the two measured sealing effectiveness parameters, as shown in Figure 11, it can be seen that there are similarities between $\varepsilon_{T}$ and $\varepsilon_{C}$ at $\mathrm{r} / \mathrm{b}=0.99$ in the buffer cavity. As both the axial and radial clearances of the seal are relatively large, a high level of ingestion is expected, hence it is not surprising that the temperature measured at the buffer cavity is close to that of the annulus. In the rotor stator cavity, the differences between $\varepsilon_{T}$ and $\varepsilon_{C}$ are much larger, showing that the effect of conduction and windage heating need to be de-coupled from $\varepsilon_{T}$ to allow it to give a clear view of the interaction between the annulus and purge flows. 


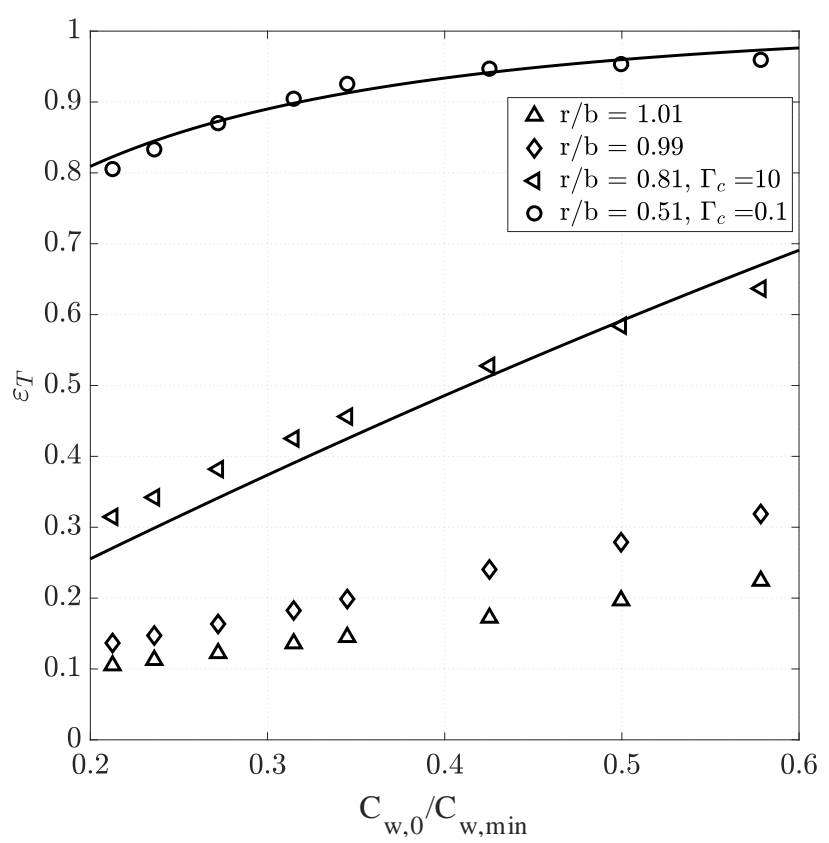

Figure 10. Sealing effectiveness using air temperature measurements on the upstream stator cavity walls

\section{Efficiency Variation}

The turbine stage performance can be quantified for various purge flow rates using either the brake efficiency or the thermal efficiency formulation. Both are evaluated as total-to-total efficiencies and as shown in the equations 9 and 10 respectively. For the brake efficiency, the turbine output power is measured as the product of the rotational speed $(\Omega)$ and the torque $(\tau)$ as measured using the dynamometer load-cell. The thermal efficiency is evaluated as a stage isentropic efficiency where the isentropic temperature ratio is calculated using the measured pressure ratio across the turbine

$$
\begin{gathered}
\eta_{\text {Brake }}=\frac{\Omega \tau}{\dot{m} C_{p}\left(T_{01}-T_{02^{\prime}}\right)} \\
\eta_{\text {Thermal }}=\frac{T_{01}-T_{02}}{T_{01}-T_{02^{\prime}}}
\end{gathered}
$$

where $T_{01}$ is the total temperature measured at the inlet, $T_{02}$ is the total temperature measured at the outlet and $T_{02^{\prime}}$ is the calculated isentropic total temperature at the outlet. The two measured total temperature values are an average of radial rakes which all include five probes equally spaced, in three locations around the circumference. In both definitions the addition of the purge flow is not included for the mass flow rate used.

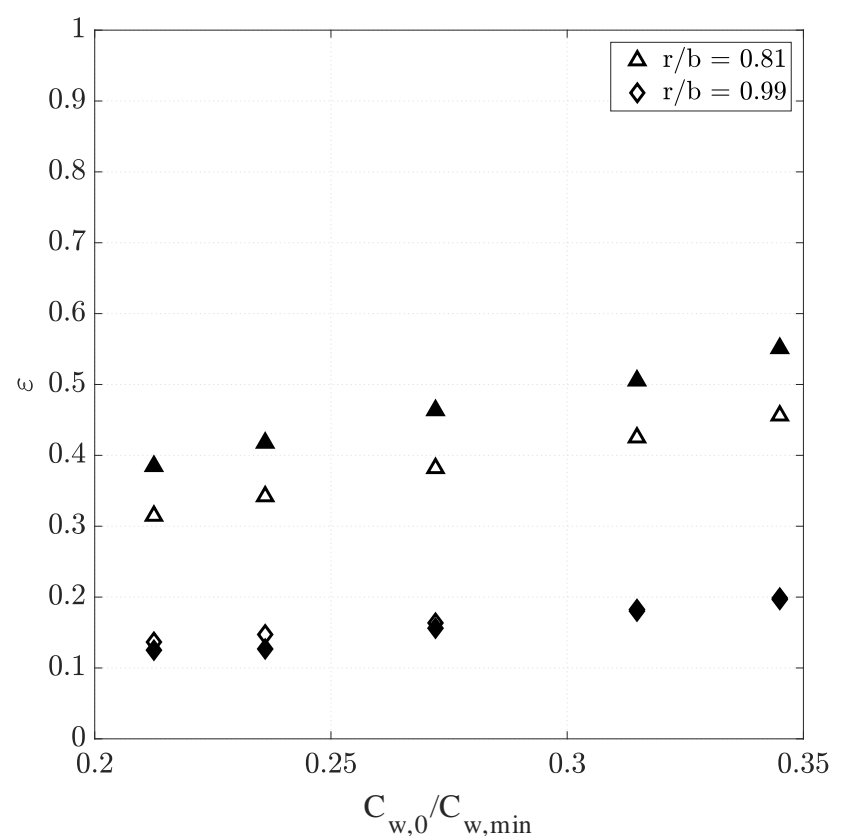

Figure 11. Sealing effectiveness for $0.81 \leq \mathrm{r} / \mathrm{b} \leq 0.99$ of $\varepsilon_{T}$ (un-filled symbols) and $\varepsilon_{C}$ (filled symbols)

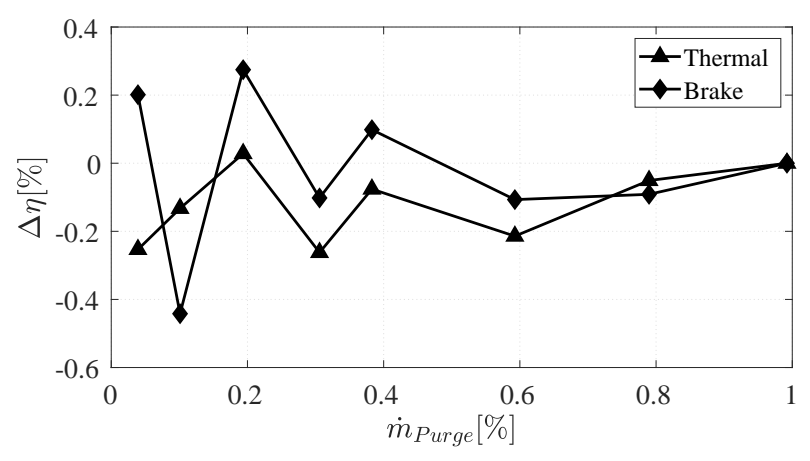

Figure 12. Percentage change in turbine stage efficiency at all purge flow rates with respect to that at maximum purge flow

Figure 12 shows the change in turbine stage efficiency $(\Delta \eta)$, evaluated as mentioned above, at all purge flow rates with respect to that at the maximum purge flow. Although one would expect the turbine performance to improve as the purge rate is decreased it is clear that there is no obvious trend in the calculated efficiencies for the range of purge flows tested. The maximum purge flow used is only $1 \%$ of the main flow and at these flow rates the efficiency changes are not discernible with the current instrumentation. Both efficiency evaluations show similar trend and some level of scatter at low purge rates. The only parameter that is common to both these efficiency definitions is the isentropic 
TABLE 2. Uncertainty Values of Major Parameters

\begin{tabular}{lll}
\hline Parameter & Value & Units \\
\hline Temperature, Stationary & 1.2 & $\mathrm{degC}$ \\
Temperature, Rotating & 0.5 & $\mathrm{degC}$ \\
Pressure & 415 & $\mathrm{~Pa}$ \\
Carbon Dioxide Concentration & 0.1 & $\%$ \\
Mass Flow Rate, Annulus & 0.25 & $\mathrm{~kg} / \mathrm{s}$ \\
Mass Flow Rate, Purge & 0.8 & $\mathrm{~g} / \mathrm{s}$ \\
Displacement & 5 & $\mu \mathrm{m}$ \\
Speed & 17 & $\mathrm{RPM}$ \\
Torque & 0.5 & $\mathrm{Nm}$ \\
\hline
\end{tabular}

temperature drop evaluated across the stage. It is possible therefore that the origin of this scatter is related to the stage inlet flow conditions.

\section{UNCERTAINTY ANALYSIS}

An uncertainty analysis has been completed for all the instrumentation that is installed on the RiSe Rig. Table 2 lists all the calculated values which are relevant to the data that has been presented.

\section{CONCLUSION}

This paper describes a newly commissioned single stage axial turbine test rig which is capable of investigating the interaction between the main annulus flow and the sealing air.

- The main auxiliary systems have been described in detail, including the equipment required for supplying the multiple air sources.

- The details of the test section of the RiSe rig have been presented, including an overview of the design and materials for the major components, the paths of both the main annulus supply and sealing air and the rim seal region geometry parameters.

- An overview of the main temperature and $\mathrm{CO}_{2}$ concentration instrumentation used to measure the ingress of the annulus air into the rotor stator cavity has been shown. Additional instrumentation essential for operating the RiSe rig has also been described.

- Transient plots of air and metal temperatures and tip clearance in the annulus show how the reduction in mass flow of the purge air effect these locations within the test section.
- Non-dimensional measurements of temperature show the effects of reducing purge mass flow rate in the rotor stator cavity. As the purge flow is reduced the temperature difference between the metal and air TCs located in the rotor stator cavity reduces, suggesting increased levels of ingestion.

- Sealing effectiveness has been calculated using measurements of both $\mathrm{CO}_{2}$ concentration and air temperature in the rim seal region. Comparisons with a theoretical model show good agreement at some locations, however at others it is not possible to achieve a match. The cause of this is postulated to be the leakage of cavity air through the disc post as this is not included in the theoretical model.

- Thermal and Brake efficiencies are compared to understand whether the reduction of purge flow has an effect on the turbine performance. The results show no trend in the efficiencies related to the reduction in the purge supply for the range tested.

\section{ACKNOWLEDGMENT}

This research would not have been possible without the skills and knowledge of our in-house technician Mr. Simon Davies. Thanks also go to Prof. Alan Turner for his help and advice with the running of the Rolls-Royce Dart engine.

\section{NOMENCLATURE}

$\begin{array}{ll}\text { A } & \text { Area } \\ \mathrm{b} & \text { Seal radius }(\mathrm{m}) \\ \mathrm{c} & \text { Concentration }(\%) \\ C_{d, e} C_{d, i} & \text { Discharge coefficients for egress or ingress } \\ C_{p} & \text { Specific heat capacity of air }(\mathrm{J} / \mathrm{K} \mathrm{kg}) \\ C_{p, \text { max }} & \text { Pressure coefficient }\left[=\Delta p /\left(1 / 2 \rho \Omega^{2} b^{2}\right)\right] \\ C_{w} & \text { Non-dimensional flow rate }[=\dot{m} / \mu b] \\ C_{w, m i n} & \text { Minimum non-dimensional flow rate to prevent ingress } \\ \mathrm{CFD} & \text { Computational Fluid Dynamics } \\ \mathrm{DAQ} & \text { Data Acquisition } \\ \mathrm{EI} & \text { Externally Induced } \\ G_{c} & \left.\text { Seal-clearance ratio [ }=s_{c} / b\right] \\ \mathrm{HE} & \text { Heat Exchanger } \\ \mathrm{K} & \text { Empirical constant } \\ \dot{m} & \text { Mass flow rate }(\mathrm{kg} / \mathrm{s}) \\ \mathrm{M} & \text { Mach number } \\ \mathrm{NGV} & \text { Nozzle Guide Vane } \\ \mathrm{P} & \text { Pressure (bar) } \\ \mathrm{PR} & \left.\text { Pressure Ratio [ }=P_{01} / P_{03}\right] \\ \mathrm{PRT} & \text { Platnium Resistance Thermometer } \\ \mathrm{PS} & \text { Purge Supply } \\ \mathrm{s} & \text { Axial rotor spacing }(\mathrm{m}) \\ s_{c} & \text { Seal clearance } \\ \mathrm{r} & \text { Local radius }(\mathrm{m}) \\ \mathrm{R} & \text { Radius ratio [ }=\mathrm{r} / \mathrm{b}]\end{array}$




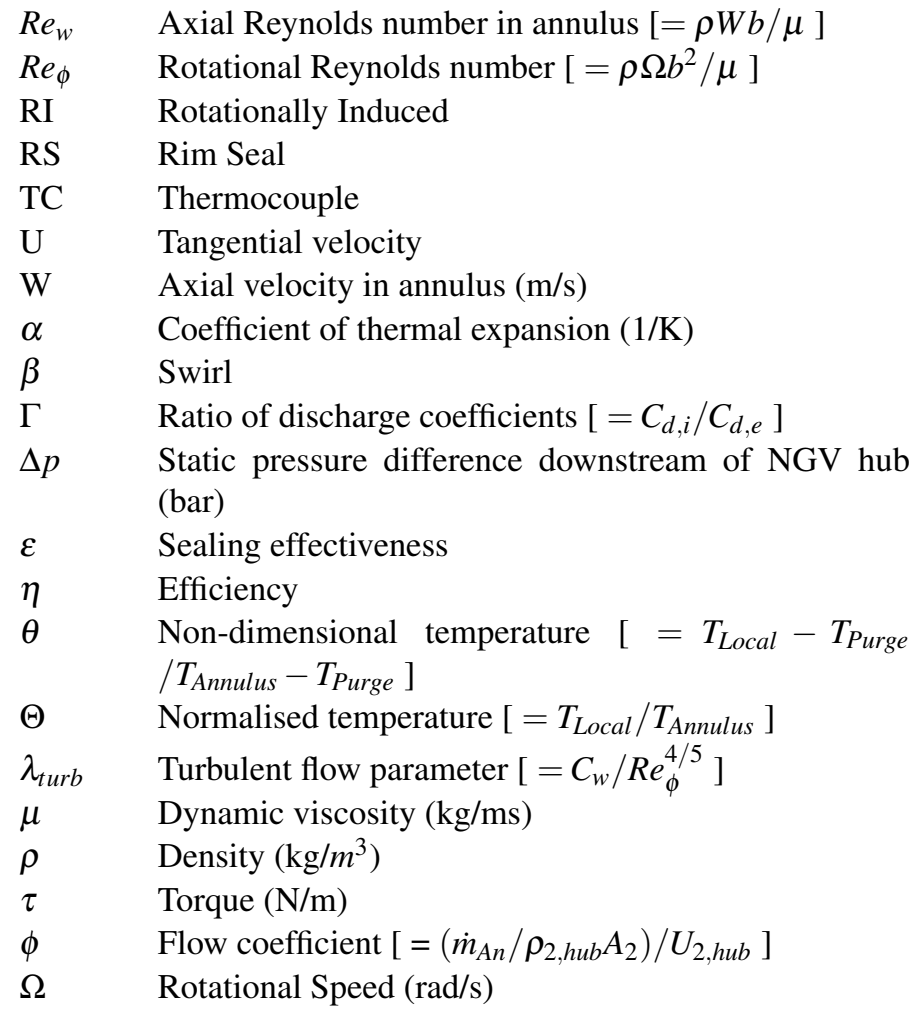

\begin{tabular}{ll}
\multicolumn{2}{l}{ Subscripts } \\
An & Annulus \\
ax & Axial-clearance \\
i & Inlet \\
max & Maximum \\
min & Minimum \\
rad & Radial-clearance \\
0 & Total condition \\
1 & Vane inlet \\
2 & Inter bladerow \\
3 & Rotor outlet
\end{tabular}

\section{REFERENCES}

[1] Bayley, F., and Owen, J., 1970. "Fluid dynamics of a shrouded disk system with a radial outflow of coolant". Journal of Engineering for Power, 92, pp. 335-341.

[2] Phadke, U., and Owen, J., 1988. "Aerodynamic aspects of the sealing of gas-turbine rotor-stator systems, part 1: The behaviour of simple shrouded rotating-disc systems in a quiescent environment". International Journal of Heat and Fluid Flow, 9, pp. 113-117.

[3] Abe, T., Kikuchi, J., and Takeuchi, H., 1979. "An investigation of turbine disk cooling (experimental investigation and observation of hot gas flow into a wheel space)". ASME Paper GT30.
[4] Phadke, U., and Owen, J., 1988. "Aerodynamic aspects of the sealing of gas-turbine rotor-stator systems, part 3: The effect of non-axisymmetric external flow on seal performance". International Journal of Heat and Fluid Flow, 9, pp. 113-117.

[5] Green, T., and Turner, A., 1994. "Investigation into the upstream wheelspace of an axial turbine stage". ASME Journal of Turbomachinery, 116(2), pp. 327-332.

[6] Gentilhomme, O., Hills, N., Turner, A., and Chew, J., 2003. "Measurement and analysis of ingestion through a turbine rim seal". ASME Journal of Turbomachinery, 125(3), pp. 505-512.

[7] Dixon, J., Brunton, I., Scanlon, T., Wojciechowski, G., Stefanis, V., and Childs, P., 2006. "Turbine stator well heat transfer and cooling flow optimisation". ASME paper GT2006-90306.

[8] Eastwood, D., Coren, D., Long, C., Atkins, N., Childs, P., Scanlon, T., and Valencia, A. G., 2012. "Experimental investigation of turbine stator well rim seal, re-ingestion and interstage seal flows using gas concentration techniques and displacement measurements". Journal of Engineering for Gas Turbines and Power, Vol 134 / 082501-1 - 082501-9.

[9] Palafox, P., Ding, Z., Bailey, J., Vanduser, T., Kirtley, K., Moore, K., and Chupp, R., 2013. "A new 1.5-stage turbine wheelspace hot gas ingestion rig (hgir) - part 1: Experimental test vehicle, measurement capability and baseline results". ASME paper GT2013-96020.

[10] Patinios, M., Scobie, J., Sangan, C., Owen, J., and Lock, G., 2016. "Measurements and modelling of ingress in a new 1,5-stage turbine research facility". ASME paper GT201657163.

[11] Eastwood, D., 2014. "Investigation of Rim Seal Exchange and Coolant Re-Ingestion in Rotor Stator Cavities Using Gas Concentration Techniques". PhD Thesis, University of Sussex, Brighton, June.

[12] Turner, A., Davies, S., Childs, P., Harvey, C., and Millward, J., 2000. "Development of a novel gas turbine driven centrifugal compressor". Proc. Instn. Mech. Enngrs. Vol. 214, Part A, pp. 423-437.

[13] Daily, J., Ernst, W., and Asbedian, V., 1964. "Enclosed rotating discs with superimposed throughflow". Department of Civil Engineering, Hydrodyn. Lab., MIT Rep. No. 64.

[14] Owen, J., 2011. "Prediction of ingestion through turbine rim seals_-part ii: Externally induced and combined ingress". ASME J. Turbomach., Vol. 133, Issue 3, 031006-1 to 9.

[15] Sangan, C. M., Pountney, O. J., Zhou, K., Wilson, M., Owen, J. M., and Lock, G. D., 2011. "Experimental measurements of ingestion through turbine rim seals. part 1: Externally-induced ingress". ASME Paper GT2011-45310. 